\title{
MODEL OF TRANSPORTATION MODE SELECTION BETWEEN PRIVATE VEHICLE AND SERPONG- TANAHABANG COMMUTER LINE
}

\author{
A Y Nurhidayat ${ }^{1}$, H Widyastuti $^{2}$, Sucipto $^{3}$, D P Utomo ${ }^{4}$ \\ 1. Sepuluh Nopember Institute of Technology, 2. Sepuluh Nopember Institute \\ of Technology, 3. Agency For The Assesment and Application of \\ Technology, 4. Agency For The Assesment and Application of Technology \\ $\square$ corresponding author: asepyayat.nurhidayat@gmail.com
}

\begin{abstract}
Transportation demand from Bodetabek to Jakarta during the period of 2002 up to 2010 has increased by $\pm 20 \%$ per year. While the growth of the road network in the same period only grew $0.01 \%$ per year. This condition is so unbalanced that the efficiency of road space usage must be done, one of which is by increasing the role of public transportation especially by promoting the use of mass transportation based on rail road as the mode choice in doing daily trip. This research was conducted to analyze the model of transportation mode selection between private vehicle and Serpong-Tanahabang commuter line route as an empirical case study. Revealed Preference techniques and binomial logit model are used in this study as tools for data collection and processing. We found that with the operation Serpong-Tanahabang commuter line route thas a negative impact on private vehicle demand because a big number of passengers preferred commuter line over private vehicle service because fast travel time and less travel cost.
\end{abstract}

Keywords: demand, public transportation, mode choice, commuter line, revealed preference

\section{Introduction}

Jakarta as the capital of the Republic of Indonesia, became the center of economic activity of the country. The many economic activities in Jakata cause transportation problems such as traffic congestion on the road, decreasing air quality, loss of time value and so on. The problem of congestion due to the use of private vehicles is not only happening in Jakarta, but also on the connecting roads of Jakarta with the supporting areas of Bogor, Depok, Tangerang and Bekasi (Jabodetabek). Increasing congestion due to private use encourages the government to continue improving and adding transportation facilities and infrastructure. The development of facilities and infrastructure is carried out to improve the services of public transportation especially related to the use of mass transportation. 
The complexity of mobilization of people living in urban areas Indonesia is often not supported by the availability of infrastructure and modes adequate public transport. The continued growth of population increasingly requires the central government and local governments to do anticipation of the provision of public transportation services that can accommodate those interests. One of the specific features of urbanization at Indonesia is an increasing city with metropolitan categories (Ashari, 2016).

In the era of globalization and technology that has been very advanced and develop, then, the transport sector holds an important role because it makes it easier for people to reach a place to a certain purpose (Haryono, 2016).

Public transport is one of the economic growth pulse, especially in urban areas. Public transport can not be separated from the planning and growth of areas where public transport is very big role in supporting community activities. Public transport becomes the main choice for moving needs for most people, especially middle to lower class society. In the context of urban transport, public transport is a vital component affecting urban transport systems. A good, well-planned, and well-coordinated public transport system will improve the effectiveness and efficiency of urban transport systems.

Meanwhile, when viewed from the change in the use of vehicles for the trip (trip by mode) in the Jabodetabek area for the year 2002 compared to the year 2010 increased $27.5 \%$ for motorcycle users. On the other hand there is a decrease in the use of public transport (buses, trains, motorcycles) of $28.4 \%$. Changes in vehicle usage in Jabodetabek area for the year of 2002 compared to 2010 are complete as follows: 
Table 1. Mode Share

\begin{tabular}{cccccc}
\hline Year & Motorcycle & Car & Bus & Others & Total \\
\hline 2002 & $28.7 \%$ & $15.2 \%$ & $50.1 \%$ & $6.9 \%$ & $100 \%$ \\
2010 & $62.9 \%$ & $17.4 \%$ & $16.7 \%$ & $3.0 \%$ & $100 \%$ \\
\hline
\end{tabular}

Source : JUPTI Commuter Survey, 2010

The type of mass transportation technology that is still being discussed is public transportation based on road and rail based public transportation. The main factor in determining the choice of mass transportation technology mass is the amount of demand, besides that is not less important is the factor of affordability by the community. To know the factors that affect the public against the selection of modes between private vehicles with mass-based public transportation rail Serpong-Tanahabang commuter line.

Along with the development of the times, found a vehicle that can meet the increasingly complex human needs. Naturally, people want to own a private vehicle for transportation needs can be met easily. This is certainly causing problems in big cities like Jakarta. Jakarta as the capital of the State creates a need for greater economic activity compared to other cities. The impacts caused by the high activity are air pollution caused by exhaust gas from motor vehicles and, road capacity that can not accommodate vehicle volume (Tamin, 2000).

The choice of mode is one of the important models in transportation planning both for the government as the builder and provider of transportation system as well as for transportation service entrepreneurs in making decisions to invest in public transportation. In addition, the selection of appropriate mode can also be the basis of consideration for public transport operators in seizing the market and increasing the competitiveness between modes by increasing the utility of travel attributes.

The transportation service industry, especially ground transportation like railway, is one of the most strategic industries at this time. This is 
because the need for cheap transportation services for lower middle class society in Indonesia is an urgent need (Haris, 2016).

The need for land transportation management effectively in the sense of cheap, smooth, fast, easy, organized and comfortable is a demand from the community (Kadarisman, 2016). At present, the service industry of various transportation modes is increasingly widespread in Indonesia (Saribaonon, 2016).

The commuter train is a rail-based transport system that connects the central business district in the urban areas with the suburban. Commuter trains are organized to serve commuters or commuters operated by PT. Kereta Komuter Indonesia.

Model of mode of transportation is modeling or stages of the transportation planning process that serves to determine loading travel or knowing the number (in terms of proportion) of people and goods that will use or choose different modes of transportation available to serve a particular point of origin, for the sake of some intent certain trips also. (Tamin, 2000)

In general, the discrete selection model is expressed as the chances each individual chooses an option is a function of the socio-economic trait and the appeal of that choice. To express the appeal of an alternative, use the concept of utility. Utility is defined as something that is maximized by the individual. The alternative does not produce utility, but is derived from its characteristics and from each individual. (Landcaster, 1966 in Tamin, 2008).

In the preference survey, two approaches are known. The first approach is the revealed preference (RP) and satated preference (SP). The revealed preference technique analyzes community choices based on existing reports. Using the statistical techniques identified factors that elicit the election. The revealed preference technique has the disadvantage of predicting an individual's response to a state of service that is not present at the present time and may be much different from the current situation (Ortuzar and Willumsen, 2001). 
The enhancement of services provided by the Serpong-Tanahabang commuter line is intended to fulfill the public's desire for public transport that has adequate travel comfort, high speed, efficient, reliable and affordable by people's purchasing power.

Given the alternatives to the selection of the two modes of public transport, it is considered necessary to analyze the modeling of the behavior of prospective users of the Serpong-Tanahabang commuter line with private vehicle users. So with the modeling of mode selection in this research can be known attributes that influence in the selection of modes, trends and the amount of demand for private vehicle users on the Serpong-Tanahabang commuter line.

In line with the formulation of the problem. Then, will be tested some the hypothesis is basically a conclusion that is while, which will be proven through statistical tests. As for hypotheses proposed in this study are as follows:

a. Independent variables that affect the users of private vehicles in determining the choice of using Serpong-Tanahabang commuter line.

b. How much is the probability of moving private vehicle users to Serpong-Tanahabang commuer line.

\section{Method}

One of the elements in the framework of data collection in this study is the design and implementation of field surveys. The survey was conducted in BSD hinterland area, Serpong station area, Rawabuntu station area. The point is chosen by considering the location is still around the study area and located around the station so it is very easy to access to the station. The condition of the study sites also meruakan commercial areas, education, offices, and housing will offer a sample of respondents who are quite heterogeneous. Jam station location also occurs transfer between modes that are competed to facilitate the process of data retrieval.

The model developed in this research uses the RP technique because the two modes are already in operation, this technique requires input 
variables such as passenger characteristics (age, education, occupation, and other socio-economic) and other travel attributes that are considered to have a major effect on the behavior of the election mode. Implementation of the survey of passenger characteristics and selection of these modes is carried out very effectively and directly at the level of individual passengers in order to obtain appropriate information for this research. In this survey, respondents were offered a number of travel attributes offered in relation to the modes to be reviewed in this study.

The main survey was conducted after the design of the questionnaire fulfilled the requirements. Respondents should be guided to complete the questionnaire completely and not allowed to select more than one option. In addition, data inconsistencies and fanatism in certain modes should be avoided so that users' responses to changes in travel attributes and the addition of new modes can be well observed. The main survey examines the competition between private vehicle users and the Serpong-Tanahabang commuter line. Users of each mode only compare the usual mode of use, so there will be models that will represent the chance of passenger selection of a mode.

\section{Selecting choice variabel dependent}

Binary logistic regression method were used to analyze how much the private vehicle willingness will move using Tanahabang-Serpong commuter line, where variables are dichotomized with two possibilities (1: yes and 0: no). The answer YES for those who want to move using TanahabangSerpong commuter line and NOT for those who still want to use private vehicle mode.

\section{Selecting choice variabel independent}

In our revealed preference design, there are transportation modes on the Serpong-Tanahabang commuter line: private vehicle and SerpongTanahabang commuter line as an alternative mode of transportation. As discussed in previous sections, the authors decided to use not travel time and travl cost. It is necessary to set the evels of value of these two variables. 
Authors too include variables gender, age, income level, job, educattion level, trip purpose and the modes used to the airport.

\section{Travel time attribute}

Travel time is the travel time of the vehicle in minutes or hours, which is the time required to start the journey from the starting point until arriving at the destination. The average travel time of private vehicle SerpongTanahabang from major cities was $120 \mathrm{~min}$.

\section{Travel cost attribute}

Travel costs incurred for the payment of the transportation fee in rupiah per person, which is the cost of the Serpong-Tanahabang route as fuel vehicle, freeway ticket and parking.

\section{Structure of the questionnaire}

As described in previous sections, two factors which influence transport modal choice behaviour were determined as attributes for the RP experiment: travel costand travel time. Three levels were assigned for each attribute. Table 1 shows the fractional factorial plan of combinations of attribute levels. This fractional factorial plan is based on the catalogue of fractional factorial designs found in the Orthogonal Experimental Design Table (Hahn and Shapiro, 1966). Following the design table 1, the test plan code corresponds, and then by applying the master plan number, which can be designated as questions can be created by the Hahn's table. The alternative experimental designs shown in Tables 2.

Table 2. Values Of Each Attribute Level

\begin{tabular}{cccc}
\hline & \multicolumn{2}{c}{ Value of each attribute level (differences private vehicle and } \\
Attribute & commuter line) & \\
\cline { 2 - 4 } & Level 1 & Level 2 & Level 3 \\
\hline Travel Cost (IDR) & -35.000 & -30.000 & -20.000 \\
Travel Time (Min) & +30 & +45 & +60 \\
\hline
\end{tabular}




\section{Revealed preference survey and model calibration}

In general, the sample size for the stated preference survey should be large enough to accommodate at least 75-100 numbers for each attribute or segment, examples of which include gender, income level, job, age and trip purpose, which are determined by the intention and purpose of the analysis (Bradely and Kores, 1990; Kim, 2001; Park, 2006).

In general, regression analysis is essentially a study of dependent variables with one or more independent variables in order to estimate and / or predict the average population or the mean value of the dependent variable based on the value of the known independent variable. The result of regression analysis is a coefficient for each independent variable. This coefficient is obtained by predicting the value of the dependent variable with an equation. The regression coefficient is calculated with the aim of minimizing the deviation between the actual value and the estimated value of the dependent variable based on the available data.

In the binomial logit model the decision is confronted with a pair of discrete alternatives, in which the alternatives to be chosen are those with the greatest utility. The utility in this case is seen as a random variable. The logistic regression model is a nonlinear model with which a transformation can be brought to a linear form. To get the linear form, then logistic regression transformed into logit form that is formula 1.

$$
\ln \frac{p}{1-p}=\beta_{0}+\beta_{1} X 1+\beta_{2} X 2 \ldots \ldots+\beta_{n} X n
$$

The choice probabilities of the logit model is the integral calculus of the choice probability in the density of parameters as shown in formula 2.

$$
\mathrm{P}=\frac{\exp \left(\beta_{0}+\beta_{1} X\right)}{1+\exp \left(\beta_{0}+\beta_{1}\right)}
$$

\section{Discussion and Result}

The questionnaire was prepared and issued by the surveyors directly to the respondents and collected immediately. The survey was conducted on 70 respondens in BSD area, Serpong Station and Rawabuntu station. The 
questionnaire was organized to collect data on gender, age, income level, job, educattion level, trip purpose, in addition to other measurements asked for in general documentary records and the documentation of the revealed preference test.

Table 3. Survey Result

\begin{tabular}{|c|c|}
\hline Variable & Percentage \\
\hline Gender & Male : $67.1 \%$, Female : $32.9 \%$ \\
\hline \multirow{5}{*}{ Educattion level } & Junior high school : $4.3 \%$ \\
\hline & Senior high school : $14.3 \%$ \\
\hline & Diploma : $4.3 \%$ \\
\hline & Bachelor : $60.0 \%$ \\
\hline & Postgraduate : $14.3 \%$ \\
\hline \multirow{5}{*}{ Job } & Goverment employee : $10.3 \%$ \\
\hline & Employee : $47.1 \%$ \\
\hline & Businessman : $25.0 \%$ \\
\hline & Student : $2.9 \%$ \\
\hline & Other : $14.7 \%$ \\
\hline \multirow{6}{*}{ Income level } & IDR $3.000 .000: 11.4 \%$ \\
\hline & IDR $3.000 .000-5.000 .000: 20.0 \%$ \\
\hline & IDR 5.000.000 - 7.000.000: 40.0\% \\
\hline & IDR $7.000 .000-9.000 .000: 22.9 \%$ \\
\hline & IDR $9.000 .000-11.000 .000: 4.3 \%$ \\
\hline & IDR $11.000 .000-13.000 .000: 1.4 \%$ \\
\hline \multirow{6}{*}{ Trip purpose } & Work : $75.7 \%$ \\
\hline & Social : $12.9 \%$ \\
\hline & Recreation : $2.9 \%$ \\
\hline & Business : $2.9 \%$ \\
\hline & Study : $2.9 \%$ \\
\hline & Other : $2.8 \%$ \\
\hline
\end{tabular}

The respondents gender was broken down as $67.1 \%$ male and $32.9 \%$ female, resulting in a passengers gender ratio of about 2:1. The purpose trip for work $75 . \%$, Social $12.9 \%$, business were about $2.9 \%$, and $8,7 \%$ was for other reasons. These other reasons were for travel in general and specifically vacation, recreation, returning home, etc. 
A characteristic that influences the respondent in determining the choice of using Serpong-Tanahabang commuter line, is said to be significant if the value of $\operatorname{sig}<\alpha$, where $\alpha$ is in this analysis the value of $\alpha$ is $10 \%$.

Table 4. Significance Test Results Used Logistic Regression

\begin{tabular}{|l|c|}
\hline Independent Variable & Significance $(\alpha)$ \\
\hline Gender & 0,11 \\
\hline Education level & 0,26 \\
\hline Job & 0,55 \\
\hline Income level & 0,02 \\
\hline Trip Purpose & 0,32 \\
\hline
\end{tabular}

Shown in table 4 above shows only variable income level that has a significant value of 0.02 or less than $\alpha<0.1$ (The value is said to be significant because the value of $\operatorname{sig}<\alpha$, where $\alpha$ is the value in this analysis the value of $\alpha$ is $10 \%$ or 0.1 ).

Table 5. Model Calibration Results

\begin{tabular}{|l|c|}
\hline \multicolumn{1}{|c|}{ Coefficient } & Value \\
\hline Income level & -0.287 \\
\hline Constant & 2,330 \\
\hline$\alpha$ & 0,02 \\
\hline Travel Cost (IDR) & -20.000 \\
\hline Travel time (min) & +60 \\
\hline
\end{tabular}

From table 5 can be seen the significant variables to influence the respondents choose Serpong-Tanahabang commuter line (travel cost 20.000 and travel time $+60 \mathrm{~min}$ ) is the income level IDR 6 million. From table 5 for the logit equation is obtained as follows:

$$
\begin{aligned}
\operatorname{logit}(P) & =\frac{p}{1-p}=\beta_{0}+\beta_{1}(X) \\
& =2.330-0.287 \text { (Income level IDR } 6 \text { million) } \\
& =0.611 \\
& P=\frac{\exp ^{\operatorname{logit}(p)}}{1+\exp ^{\operatorname{logit}(p)}}=\frac{\exp ^{0,611}}{1+\exp ^{0,611}}
\end{aligned}
$$




$$
P=\frac{2.718^{0,611}}{1+2.718^{0.611}}=0.6481 \sim 65 \%
$$

So the chances of passenger private vehicle that will move using Serpong-Tanahabang commuter line is a income level of IDR 6 million of $65 \%$. The analysis results are based on respondence used private vehicle. Obviously for motorcycle has a characteristic or selection of different modes with the above model due to the existence of different independent variables that influence in the selection of modes.

\section{Conclusion}

The goal of this research was to analyse mode choice private vehicle and Serpong-Tanahabang commuter line. The analyzed only one variables, namely income level. The result obtained from the analysis showed that only $65 \%$ of passengers would prefer to travel by Serpong-Tanahabang commuter line. Therefore, a big number of passengers preferred commuter line over private vehicle service because fast travel time and less travel cost.

This study had certain limitations in analyzing passengers preferences on the Serpong-Tanahabang route because the only variable which influence the model. Also, the actual commeter line service frequencies were shown to be much longer than assumed in this paper because waiting time in station, delay, walking time etc. Therefore, the interdependent relationship between the two modes private vehicle and Serpong-Tanahabang in terms of high speed transport will be an area of continuing interest for researchers. It appears that more time is needed to see the stabilization of the operating system of commuter line before more detailed analyses can be made.

Additional variables used in advanced studies were found to influence the behavioral mode of transportation options of each type of passenger. Values representing the coefficients of each model variable show a slight significance value with the additional variables applied to the model.

\section{References}

Ashari, Y. , and Setyowati, T.M. (2016). Leverage Analysis Increase Progressive Rate And Commuter Line Warranty To The Passenger 
Expected Level (Case Study Bogor - Manggarai Road), Journal of Business Management of Transportation and Logistics, Vol. 2 No. 3, May 2016.

Directorate General of Highways. (1995). Indonesian Highway Capacity Manual Part 1. Urban Road, Directorat General of Highways, Ministry of Public Works, Jakarta.

Haris., et al. (2016). Predicting Business Continuity of PT KAI Through Altman Z-Score Approach, Journal of Transportation \& Logistics Management (JMTranslog) - Vol. 03 No. 1, March 2016.

Haryono., et al. (2016). Analysis Of Effect Of Price And Quality Of Service To Customer Satisfaction Pt. Dms Tour And Travel, Journal of Transportation and Logistics Business Management, Vol.2 No. 2, January 2016.

Hess, S., Polak, J.W. (2005). Mixed logit modeling of airport choice in multi-airport regions. J. Air Transp. Manag. 11, 59e68.

Kadarisman, M., et al. (2016). Land Transport Management Policy and Its Impact on People's Economy in Depok City, Journal of Transportation \& Logistics Management (JMTranslog) - Vol. 03 No. 1, March 2016.

Lee, J.-K., et al. (2016). A study on travelers' transport mode choice behavior using the mixed logit model: A case study of the Seoul-Jeju route, Journal of Air Transport Management. http://dx.doi.org/10.1016/j.jairtraman.2016.04.020

Ortuzar, J.D. , and Willumsen, L.G. (2001). Modelling Transport $3^{\text {rd }}$ edition, John Wiley and Sons Ltd, England.

Park, Y., Ha, H.-K., 2006. Analysis of the impact of high-speed railroad service on air transport demand. Transp. Res. Part E 42 (2), 95e105.

Pearmain, D., Swanson, J., Kroes, E., Bradley, M. (1991). Stated Preference Techniques : A Guide to Practice $2^{\text {nd }}$ Edition, Steer Davies Gleave and Haque Consulting Group, London.

Puthcer J. et al. (1981). The Socioeconomic Characteristic of Transit User Some Recent Evidence, Transportation Quartelly, USA.

Saribanon, E., et al. (2016). The Satisfaction Of Transportation's Customers To Enchance Loyalty, Journal of Transportation \& Logistics Management (JMTransLog) - Vol. 03 No. 03, November 2016.

Stubs, P.C., Tyson W.J., dan Dalvi, M.Q. (1980). Transport Economics, George Allen and Unwin (Publisher)Ltd., London.

Tamin, Ofyar Z. (2000). Planning and Modelling Transportation. Bandung, Indonesia: Publisher ITB

Tamin, Ofyar Z. (2008). Planning and Modelling Transportation. Bandung, Indonesia: Publisher ITB 